\title{
Plastic adaptations of foraging strategies to variation in forage quality in Alpine chamois
}

\author{
Arno Puorger (A.P.) ${ }^{1,2}$, Christian Rossi (C.R.) ${ }^{2,3,4}$, Rudolf M. Haller (R.H.) ${ }^{2}$, Pia Anderwald \\ (P.A.) $^{2}$ \\ ${ }^{1}$ University of Natural Resources and Life Sciences, Gregor-Mendel-Strasse 33, 1180 Vienna, Austria \\ ${ }^{2}$ Swiss National Park, Chastè Planta-Wildenberg, 7530 Zernez, Switzerland \\ ${ }^{3}$ Department of Geography, University of Zurich, Winterthurerstrasse 190, 8057 Zurich, Switzerland \\ ${ }^{4}$ Swiss Federal Research Institute WSL, Zürcherstrasse 111, 8903 Birmensdorf, Switzerland
}

\begin{abstract}
Foraging efficiency strongly affects individual fitness and is influenced by diverse factors such as the food quality and quantity, as well as intra- and interspecific interactions. We investigated whether Alpine chamois (Rupicapra rupicapra L., 1758) in a protected area in the Swiss Alps adapted their foraging behaviour to forage availability and quality by modeling the bite and step rates of individuals on vegetation nitrogen content, relative plant cover, sex, daytime, air temperature and slope. Vegetation characteristics were derived using remote sensing data from airborne imaging spectroscopy datasets and feeding locations determined using a theodolite. Chamois increased their bite rates with decreasing forage nitrogen content, decreasing slope and increasing temperature. Step rates were higher at high temperatures and decreased with increasing relative plant cover. Males showed higher bite rates and lower step rates than females. Daytime had no influence on either bite or step rates. An increase in bite rate may represent a plastic adaptation of foraging behaviour to compensate for lower nutritional quality of the available vegetation. Our results show variability in foraging behaviour according to both vegetation characteristics and the physical environment and emphasize the use of remote sensing data to investigate relationships between habitat and subtle behavioural adaptations in ungulates.
\end{abstract}

\section{Keywords:}

Rupicapra rupicapra, Alpine chamois, bite rate, foraging ecology, Airborne Prism Experiment, Meris Terrestrial Chlorophyll Index, mountain ungulate

This document is the accepted manuscript version of the following article: Puorger, A., Rossi, C., Haller, R. M., \& Anderwald, P. (2018). Plastic adaptations of foraging strategies to variation in forage quality in Alpine chamois (Rupicapra rupicapra). Canadian Journal of Zoology, 96(3), 269-275. https://doi .org/10.1139/cjz-2017-0073 


\section{Introduction}

Animals living in seasonal environments experience regular fluctuations in food availability and quality. This problem increases with increasing latitude and elevation, as vegetation periods become shorter (Koerner 1999). Strong seasonality in forage availability thus necessitates specific adaptations to overcome periods when energy expenditure outweighs energy intake. It would be expected that selection pressure to maximise energy gain during the vegetation period is particularly strong in non-migratory herbivores, which should therefore also be able to readily adapt their foraging behaviour to fine-scale variation in forage availability (Bruno and Lovari 1989). As mountain environments show a fine-scale mosaic of habitats with different foraging conditions (Koerner 1999), they represent an ideal study system to observe adaptations in foraging behaviour of larger herbivores to spatial variation in food availability.

Ruminants have evolved distinct adaptations of their digestive system and foraging behaviour in response to selective pressures acting through spatial and temporal variation in nutrient quality and quantity (Hoffmann 1989). These traits contribute to their ability to occupy a wide variety of habitats across the globe. In the case of the Alpine chamois (Rupicapra rupicapra L., 1758), these adaptations are mainly targeted at optimizing energy budgets to cope with low temperatures, increased energy expenditures for locomotion and decreased energy intake due to snow cover during winter (Ingold 2005). Recently, Alpine chamois have experienced a significant population decline across a large part of their distribution range in the Swiss Alps (Federal Office of Environment, http://www.wild.uzh.ch/jagdst), but the factors driving this trend remain largely unknown.

A major driver of chamois mortality is harsh winters (Jonas et al. 2008), with scarce forage of low nutritional value. Body condition is therefore an important determinant of winter survival (Jonas et al. 2008), and Garel et al. (2011) showed a positive correlation between forage quality in early summer and autumn body mass in juveniles. Considering the high energy requirements of both sexes during this period (Ferretti et al. 2014), chamois should adopt a behaviour consistent with the most efficient energy gain. Several parameters can be correlated with daily energy intake in herbivores, such as bite rate, bite size, step rate (food selectivity) and amount of time spent foraging. In a non-invasive study design and in areas where access is limited, bite and step rates are particularly useful parameters to quantify foraging behaviour. In Rocky Mountain bighorn sheep (Ovis canadensis Shaw, 1804), for example, the bite rate of individuals was found to be dependent on sex, reproductive status, satiation and also on the animal's perception of safety (Ruckstuhl et al. 2003). Ferretti et al. (2014) demonstrated variation in bite rate according to sex and food plant species in Apennine chamois 
(Rupicapra pyrenaica Bonaparte, 1845). However, interspecific competition may also be an important factor determining efficiency of energy intake, as shown by Ferretti et al. (2015), who observed reduced bite and increased step rates in Apennine chamois on patches that were also used by red deer (Cervus elaphus L., 1758).

In an area of high red deer density in the Swiss National Park (SNP), Alpine chamois also appear to be affected by interspecific competition, indicated by a decrease in the use of meadows in favour of scree slopes, and by young animals showing reduced horn growth, when red deer abundance increased (Anderwald et al. 2015). By comparison to red deer, chamois also selected steeper slopes and meadows of lower productivity than available on average (Anderwald et al. 2016). While both chamois and red deer are mixed feeders, the digestive system and diet of red deer is more similar to that of grazers, while chamois show more similarity with browsers (Gordon and Illius 1988; Hofmann 1989; Pérez-Barbería et al. 2001). It would therefore be expected that chamois depend on higher quality forage than red deer. However, in the Swiss National Park, Alpine chamois used meadows of lower biomass but, surprisingly, similar nitrogen content as compared to red deer (Schweiger et al. 2015). It is possible that chamois are to some extent able to compensate for suboptimal feeding conditions (which may in part be caused by interspecific competitive interactions in this area) by adapting their foraging behaviour. This would allow the species to spatially and temporally adapt to a wide range of foraging conditions.

Here we investigate the foraging behaviour of Alpine chamois on meadows of different forage quality in a valley within the Swiss National Park characterised by high red deer densities during the summer based on bite and step rates. Our hypothesis was that bite rates should increase with increasing nitrogen content (i.e. increasing forage quality) of the vegetation at the grazing patch, while step rates should decrease accordingly. As no mammalian predators are present in our study area, we base our hypothesis on the fact that winter conditions are the stronger selective force over predation (Jonas et al. 2008), and the "average" individual thus follows an energy maximizing rather than a time minimizing foraging strategy (Bergman 2001). This would indicate increased foraging efficiency in higher quality patches (see also Ferretti et al. 2015). On the other hand, an increase in bite rate with decreasing nitrogen content of the vegetation (i.e. poorer foraging patches) could indicate some degree of compensation in foraging behaviour in Alpine chamois, whereby animals may increase the amount of forage intake while decreasing selectivity. 


\section{Material and methods}

\section{Study area}

Our study area was the Trupchun valley in the southern part of the SNP. The Trupchun valley has an orientation from SE to NW and covers an area of approx. $22 \mathrm{~km}^{2}$. Its elevation ranges from 1780 to $3070 \mathrm{~m}$ a.s.1.. The average annual temperature (based on data recorded at Buffalora weather station, located ca. $13 \mathrm{~km}$ from the study area) is $1.1 \pm 0.6^{\circ} \mathrm{C}($ mean $\pm \mathrm{sd})$ with a mean daily maximum temperature of $7.7 \pm 0.8^{\circ} \mathrm{C}$ and a mean daily minimum temperature of $-5.2 \pm 0.7^{\circ} \mathrm{C}(2005-2015)$. Snow cover lasts from early November to mid-April; the mean annual precipitation is $788 \pm 168 \mathrm{~mm}(2005-2015$; MeteoSwiss 2016). The growing season lasts from midMay to mid-September. During this time, the valley accommodates high numbers of red deer, Alpine chamois and Alpine ibex (Capra ibex L., 1758). The 2015 annual ungulate survey, conducted during spring and summer 2015, yielded counts of $461 \mathrm{red}$ deer (i.e. $\left.21 \mathrm{ind} . / \mathrm{km}^{2}\right), 231 \mathrm{ibex}\left(11 \mathrm{ind} . / \mathrm{km}^{2}\right)$ and 223 chamois $\left(11 \mathrm{ind} . / \mathrm{km}^{2}\right) \mathrm{in}$ the Trupchun valley. The study area is dominated by coniferous forest at altitudes below $2200 \mathrm{~m}$ a.s.1., subalpine and alpine meadows between ca. 2200 and $2600 \mathrm{~m}$ a.s.l. and scree slopes, as well as rock faces, above $2600 \mathrm{~m}$ a.s.1..

On the southwest exposed slope of the valley, where most feeding Alpine chamois were observed (Fig. 1), forests had been partly clear-cut before the area became part of the SNP. Grasslands therefore also cover areas below 2200 m.a.s.1. (Zoller 1995). The grasslands are characterized by a small-scale heterogeneous mosaic of plant communities, with up to 40 plant species per square meter (Schweiger et al. 2015). Generally, the grasslands on steep slopes are, independent of altitude, predominated by tussocks of the evergreen sedge (Carex sempervirens Vill.) and the dwarf shrub common rock-rose (Helianthemum nummularium (L.) Mill.). On flat or slightly concave landscape elements lawn grasses such as red fescue (Festuca rubra L.) and quacking grass (Briza media L.) together with rough hawkbit (Leontodon hispidus L.) become dominant. In terms of nutrient content, the steeper slopes are less nutritious than the shallower ones.

[Figure 1]

Human visitors are restricted to using the footpaths only and are not allowed to bring dogs into the park, and hunting is strictly forbidden within the SNP. Before and during completion of the study, there were no large mammalian predators in the valley or the surrounding area. Roe deer (Capreolus capreolus L., 1758) occur at very low densities and are rarely seen above the timberline where our observations took place. 


\section{Chamois foraging behaviour}

Data collection took place between 22 June and 29 July 2016, with an average of three observation days per week. Using a focal animal sampling approach, we observed foraging chamois at the age of one year and older from three pre-defined vantage points with binoculars $(8.5 \times 42)$ and spotting scopes $(20-60 \times 65)$ and recorded each bite and step taken using a handheld computer (Psion Workabout Pro 3, Psion Teklogix Inc., Mississauga, Canada). Each animal was observed during two consecutive bouts of five minutes with a short break between bouts lasting typically two, at maximum eight minutes. A bite was defined as a visible jerking motion of the animal's head while the head was kept down, and a step was defined as a forward movement of one of the animal's forelegs (see Lovari et al. 2014). The distances to the focal animal ranged from 355 to $1610 \mathrm{~m}$ with a median observation distance of $802 \mathrm{~m}$ (Fig. 2). An observation was paused when an animal was recognisably distracted from feeding due to uncommon events such as interactions with other animals or rockfall.

\section{[Figure 2]}

Observations of chamois foraging behaviour were conducted in the rear part of the Trupchun valley only, as visibility of animals is high due to lack of forest in this part of the valley. Multiple observations of the same animal during one day were avoided by noting the sex, age class (young; $1-2$ years, mid; $3-4$ years, old; 5 years and older), time of day (morning; before $10 \mathrm{am}$, noon; 10 am to $3 \mathrm{pm}$, evening; after 3 pm), reproductive status (nursing, non-nursing) and the position of the focal animal. As a proxy for food availability, we also estimated the vegetation cover within a radius of five times the body length of an adult chamois around the focal animal $(0-25 \%, 25-50 \%,>50 \%$ vegetation). We calculated bite and step rates per minute (see Bruno and Lovari 1989) and rates per five minutes, but results were very similar for both intervals, so we only present the results for five-minute intervals. In 13 observation days, we recorded 110 5-min samples with an average of eight 5-min samples per day.

For observations to be considered in the analysis, we set a minimum of 5 full minutes of observation. If the focal animal disappeared from sight or lay down during the observation, the observation was discarded.

Since observations were made only from designated picnic areas, we assume our procedures not to have evoked any behavioural responses of the chamois, as the animals are used to the presence of visitors within those designated areas along the hiking trails. 


\section{Chamois feeding locations}

The positions of the focal animal at the beginning and at the end of the observation bout was determined using a theodolite (Leica TCR 702, Leica Geosystems AG, Heerbrugg, Switzerland) measuring horizontal and vertical angles with respect to known reference points and a digital elevation model of the valley with a resolution of $2 \mathrm{x}$ $2 \mathrm{~m}$. Along with digital angle measurements, we manually registered each observed animal separately on a topographic map (1:25’000, Federal Office of Topography) and digitized the positions using the software ArcGIS (version 10.2.2, Environmental Systems Research Institute, Redlands, Ca, US). For positions that could not be successfully determined with the theodolite (due to technical issues, $n=19$ ), we used the manually entered feeding positions of the chamois.

\section{Vegetation characteristics}

We approximated the current plant nitrogen content via vegetation indices based on spectral bands of APEX (Airborne Prism Experiment, http://www.apex-esa.org/) imaging spectroscopy datasets that were generated on July $16^{\text {th }} 2016$ (see Schaepman et al. 2015 for technical details). The datasets were geometrically corrected using a parametric geo-rectification approach implemented in the PARGE software package (Schläpfer and Richter 2002), and a physically based atmospheric correction approach as implemented in the ATCOR-4 software for retrieving at surface reflectance (Richter and Schläpfer 2002) was applied. The vegetation index was selected based on the coefficient of determination $\left(R^{2}\right)$ when used as a predictor to model grassland nitrogen content as in Clevers and Gitelson (2013), where the red-edge inflection point and the MERIS terrestrial chlorophyll index (MTCI) achieved the best $R^{2}$-values ( 0.79 and 0.78 respectively). We used the MTCI, since it is an accurate indicator of chlorophyll content at all chlorophyll levels and is also suitable for use with data produced by spaceborne spectroscopes (Dash et al. 2010) such as the Sentinel satellite fleet. The MTCI is positively correlated with grassland chlorophyll content and was mapped and extracted at each registered chamois position in ArcGIS. The spatial resolution of the APEX imaging spectroscopy datasets was $2 \times 2 \mathrm{~m}$.

To account for variation in nutritional composition of vegetation along the foraging path of the focal animal, we recorded the start and end positions of each individual and assigned the positions in the right order to the two bite and step rates recorded for each animal. To capture the highest possible amount of vegetation variance in our 
data, we tried to conduct observations throughout the study area (Fig. 1). Slope was calculated from a digital elevation model in ArcGIS using the Spatial Analyst extension, and daily mean temperatures were obtained from the Federal Office of Meteorology and Climatology MeteoSwiss for the closest available weather station at Buffalora (MeteoSwiss 2016).

\section{Statistical methods}

To assess the effects of vegetation characteristics on the foraging behaviour of chamois, we modelled bite and step rates using Generalized Linear Mixed Models (GLMMs) with a Poisson error distribution for bite and step rates separately.

In the full models, we included MTCI, relative plant cover, slope, temperature, sex, and time of day (Morning, Noon, Evening) to account for daily activity patterns, as well as observer to account for observer bias. Since observer was a factor with only 4 levels, we did not include it as a random effect. Information concerning age and reproductive status was not included in the models because a clear distinction between middle-aged and old individuals was not reliable under field conditions; neither was the assignment of kids to their mothers in groups of females with their offspring. To account for individual differences in foraging strategy, we included chamois ID as a random effect in both models. Although we avoided collecting data from the same individual repeatedly during the same observation day, we could not avoid collecting data of the same individual over the whole study period since only few chamois were marked individually.

After fitting the full models, we used a stepwise backward selection procedure based on Akaike`s Information Criterion corrected for small sample sizes (AICc; Burnham and Anderson 2002). From models within $\triangle \mathrm{AICc}<$ 2, we selected the most parsimonious one. Residual plots were checked to ensure that model assumptions were met. All statistical analyses were performed using the software R 3.3.3 (R Core Team 2016). 


\section{Results}

After discarding observation bouts of less than five minutes' duration, the sample size was 106 5-minute observations of chamois. The mean number of bites $( \pm \mathrm{sd})$ per five minutes was $212.53( \pm 62.25)$, the mean number of steps was 42.25 ( \pm 27.43$)$. Bite and step rates were not correlated (Pearson's $r=-0.09)$. MTCI values at chamois foraging locations ranged from 1.27 to 2.25 , daily mean temperatures ranged from 3.6 to $14.1{ }^{\circ} \mathrm{C}$, and slopes ranged from $54 \%$ to $182 \%\left(28^{\circ}\right.$ to $\left.61^{\circ}\right)$. We collected data on 29 females and 38 males, of which one individual was classified as young, 24 individuals as middle-aged and 42 individuals as old.

[Table 1]

\section{Model results}

The final model for bite rate (Tab. 1) contained MTCI, slope, sex, temperature and the observer as explanatory variables. Bite rates increased with decreasing MTCI and decreasing slope, but increased with increasing temperatures and were higher for males than for females (Tab. 2; Fig. 3).

[Table 2]

The final model for step rate included sex, temperature and the relative plant cover around the animal (Table 1). Step rates increased with increasing temperature and decreased with increasing relative plant cover. Males showed lower step rates than females (Tab. 2; Fig.3).

[Figure 3] 


\section{Discussion}

Optimal foraging theory provides a basis for understanding the ultimate drivers of the behaviours we observe in nature. In the case of herbivorous ungulates, the two strategies opposing each other are energy maximization and time minimization (Bergman et al. 2001). The optimal strategy that is chosen by an individual is shaped by different factors and their partial contribution to an individual's relative fitness.

In the case of the Alpine chamois in a protected area lacking large mammalian predators, we expected individuals to adapt their bite rate positively to the nitrogen content of the available vegetation (see also Ferretti et al. 2015). Contrary to expectations, we found a negative relationship between vegetation nitrogen content as a proxy for forage quality and bite rate as a measure of energy intake. Nevertheless, this finding suggests that Alpine chamois do adapt their foraging behaviour to the vegetation conditions they encounter in their habitat. When competition or safety demands limit opportunities to move to more nutritious patches, animals foraging on relatively nutrient-poor vegetation should optimize their energy intake by either increasing bite rate, bite size or by spending more time foraging. We suggest that Alpine chamois pursue a more selective foraging strategy when foraging conditions are good, as indicated by the lower bite rates we found in areas of high nitrogen content, and forage less selectively in areas of lower forage quality. Ruckstuhl et al. (2003) did not find a correlation between bite rates and faecal crude protein for Rocky Mountain bighorn rams, supporting the assumption that the required daily amount of net energy intake can be reached with less cropping effort but at the same time higher selectivity of food plant species when feeding on highly nutritious vegetation as compared to poor forage quality. This strategy should allow for more time being spent on other activities such as vigilance and should thus be favoured. Step rates were negatively correlated with the relative plant cover around the animal, indicating that forage quantity also plays an important role in determining foraging efficiency, as was also observed in Apennine chamois by Ferretti et al. (2015).

In areas of poor forage quality, chamois may be forced to use low quality food resources with high fiber contents, which results in higher chewing time and thus lower bite rates. Ferretti et al. (2015) showed a negative impact of red deer density on pasture quality for chamois and decreased forage availability due to trampling and overgrazing in areas with high red deer densities, which correlated with lower bite rates compared to areas with very low deer densities. In the Trupchun valley, however, there is no indication of increased erosion on meadows due to trampling by red deer, and by contrast to Ferretti et al. (2015), our study area is characterised by generally high primary productivity (due to its mainly calcareous bedrock rather than dolomite as in other parts of the 
park; Furrer et al. 2013). Furthermore, the proportion of unpalatable and spiny plant species that are avoided by chamois was high in Ferretti et al.'s (2015) study area. Differences in foraging conditions between meadows within the Trupchun valley are therefore likely to be smaller compared to Ferretti et al.'s (2015) study areas in the Apennine, so that the situation we describe here represents fine-scale adaptations to more subtle variation in forage quality. This may partly explain the contrasting findings with respect to bite rates between the two regions.

Ferretti et al. (2014) reported differences in bite rates between male and female Apennine chamois, with males showing higher bite rates. They linked those findings to higher food selectivity of females. This is corroborated by our results: female Alpine chamois showed lower bite rates and higher step rates than males, suggesting higher search effort and thus a more selective foraging behaviour. This may be the result of a trade-off between foraging and alertness. Ferretti et al. (2014) showed a higher amount of vigilance coinciding with lower bite rates in female Apennine chamois as compared to males. However, our non-invasive study design could not capture variability in bite size, digestive turnover rate, or plant composition of chamois forage. Given the distances to the observed animals, we were unable to detect mouth movements reliably and therefore relied on the more easily detectable head movements as a measure for bite rates. The accuracy of results could possibly be improved in a further study by conducting observations on animals habituated to humans and trying to take the above factors into account.

We did not detect an effect of daytime on bite or step rates, but chamois showed higher bite and step rates with increasing temperature. A possible explanation is that chamois try to avoid high temperatures by increasing bite rate to reduce the time spent foraging (Mason et al. 2014; Brivio et al. 2016). Due to small variation in temperature in our sample, we did not detect avoidance of higher temperatures (but see Brivio et al. 2016 for chamois activity patterns in our study area).

Investigating plastic adaptations of foraging strategies in the face of vegetation variability is important to predict changes in population growth rates of mountain ungulates. Vegetation changes can be caused by abiotic (such as climatic changes) as well as biotic factors, such as competitors with partially overlapping food niches. Ferretti et al. (2015) showed a lower bite rate and a higher step rate, as well as significantly increased kid mortality, in Apennine chamois in areas with red deer compared to areas with very low densities of red deer. In a previous study in our study area, Anderwald et al. (2015) showed that horn growth (as a measure for body condition) in kids and yearlings of Alpine chamois was negatively correlated with red deer population size. Moreover, they showed that with increasing red deer numbers, Alpine chamois decreased the use of alpine meadows but 
increased the use of scree slopes. Red deer presence therefore has to be considered in longer-term studies or comparisons of foraging behaviour of Alpine chamois between different areas. However, red deer density could be assumed constant in the valley over the relatively short duration of this study and was therefore not included in the analysis. Similar effects on foraging behaviour of ungulates can be expected if human disturbance leads to permanent change in habitat use. Many studies have focused on the effects of human disturbance during winter. However, Garel et al. (2011) point out the importance of availability of high quality food instead of high quantities during the early summer months for efficient body mass gain in juvenile Alpine chamois. Adaptations in foraging behaviour might appear even more clearly towards the rut when forage quality generally decreases and chamois are forced to settle for less nutritious plant species (Ferretti et al. 2015). Thus, deepening our understanding concerning the interplay between habitat and food requirements in the face of intra- and interspecific competition is fundamental to preserve suitable habitat and as a basis for the management of this species.

Knowledge of the requirements of efficient energy acquisition during the vegetation period fills the gap between environmental changes and population demographic parameters. Remotely sensed vegetation data may therefore be a very useful tool for wildlife managers to predict likely population responses to vegetation characteristics, especially given its free availability, actuality and ever-increasing spatial resolution. Our study shows adaptations in foraging strategies in response to variation in vegetation characteristics in the Alpine chamois, likely linked to foraging efficiency and fitness of this declining mountain ungulate.

\section{Acknowledgements}

We would like to thank Silvia La Gala, Jonathan Zufferey, Samuel Wiesmann and Seraina Campell Andri for their help in the field. We also thank Mathias Kneubühler, Michael Schaepman and Martin Schütz for their useful comments on the manuscript.

\section{Funding}

This project was carried out as part of the Swiss National Park's research programme.

\section{Competing interests}

The authors declare that no competing interests exist. 


\section{References}

Anderwald, P., Haller, R. M., and Filli, F. 2016. Heterogeneity in Primary Productivity Influences Competitive Interactions between Red Deer and Alpine Chamois. PloS One, 11(1): e0146458:

doi:10.1371/journal.pone.0146458.

Anderwald, P., Herfindal, I., Haller, R. M., Risch, A. C., Schütz, M., Schweiger, A. K., and Filli, F. 2015.

Influence of migratory ungulate management on competitive interactions with resident species in a protected area. Ecosphere, 6(11): 1-18. doi:10.1890/ES15-00365.1.

Andreoli, E., Roncoroni, C., Gusmeroli, F., Della Marianna, G., Giacometti, G., Heroldová, M., Barbieri, S., and Mattiello, S. 2016. Feeding ecology of alpine chamois living in sympatry with other ruminant species. Wildl. Biol. 22(3): 78-85. doi:10.2981/wlb.00153.

Bergman, C.M., Fryxell, J.M., Gates, C.C., and Fortin, D. 2001. Ungulate foraging strategies: Energy maximizing or time minimizing? J. Anim. Ecol. 70(2): 289-300. doi:10.1111/j.1365-2656.2001.00496.x.

Bertolino, S., Di Montezemolo, N.C., and Bassano, B. 2009. Food-niche relationships within a guild of alpine ungulates including an introduced species. J. Zool. (Lond.) 277(1): 63-69. doi:10.1111/j.14697998.2008.00512.x.

Brivio, F., Bertolucci, C., Tettamanti, F., Filli, F., Apollonio, M., and Grignolio, S. 2016. The weather dictates the rhythms: Alpine chamois activity is well adapted to ecological conditions. Behav. Ecol. Sociobiol. 70(8): 1291-1304. doi:10.1007/s00265-016-2137-8.

Brivio, F., Grignolio, S., Brambilla, A., and Apollonio, M. 2014. Intra-sexual variability in feeding behaviour of a mountain ungulate: Size matters. Behav. Ecol. Sociobiol. 68(10): 1649-1660. doi:10.1007/s00265-014-1773-0.

Bruno, E., and Lovari, S. 1989. Foraging behaviour of adult female apennine chamois in relation to seasonal variation in food supply. Acta Theriol. 34: 513-523. doi:10.4098/AT.arch.89-52.

Burnham, K.P., Anderson, D.R., and Huyvaert, K.P. 2011. AIC model selection and multimodel inference in behavioral ecology: Some background, observations, and comparisons. Behav. Ecol. Sociobiol. 65(1): 23-35. doi:10.1007/s00265-010-1029-6. 
Clevers, J., and Gitelson, A.A. 2013. Remote estimation of crop and grass chlorophyll and nitrogen content using red-edge bands on Sentinel-2 and -3. International Journal of Applied Earth Observation and Geoinformation, 23: 344-351. doi:10.1016/j.jag.2012.10.008.

Corlatti, L., Bassano, B., Valencak, T.G., and Lovari, S. 2013. Foraging strategies associated with alternative reproductive tactics in a large mammal. J. Zool. (Lond.) 291(2): 111-118. doi:10.1111/jzo.12049.

Dash, J., Curran, P.J., Tallis, M.J., Llewellyn, G.M., Taylor, G., and Snoeij, P. 2010. Validating the MERIS Terrestrial Chlorophyll Index (MTCI) with ground chlorophyll content data at MERIS spatial resolution. Int. J. Remote Sens. 31(20): 5513-5532. doi:10.1080/01431160903376340.

Ferretti, F., Corazza, M., Campana, I., Pietrocini, V., Brunetti, C., Scornavacca, D., and Lovari, S. 2015.

Competition between wild herbivores: Reintroduced red deer and Apennine chamois. Behav. Ecol. 26(2): 550559. doi:10.1093/beheco/aru226.

Ferretti, F., Costa, A., Corazza, M., Pietrocini, V., Cesaretti, G., and Lovari, S. 2014. Males are faster foragers than females: Intersexual differences of foraging behaviour in the Apennine chamois. Behav. Ecol. Sociobiol. 68(8): 1335-1344. doi:10.1007/s00265-014-1744-5.

Furrer, H., Schlüchter, C., Inderbitzin, L., Pointner, E., Margreth, A., Gaar, D., and Frei, J. 2013. Geologie und Erdgeschichte. Lithologisches und zeitliches Fundament des SNP. In Atlas des Schweizerischen Nationalparks. Die ersten 100 Jahre. Edited by H. Haller, A. Eisenhut and R. Haller. Nat.park-Forsch. Schweiz 99/I. Haupt, Bern. Switzerland. pp. 16-17.

Garel, M., Gaillard, J.-M., Jullien, J.-M., Dubray, D., Maillard, D., and Loison, A. 2011. Population abundance and early spring conditions determine variation in body mass of juvenile chamois. J. Mammal. 92(5): 11121117. doi:10.1644/10-MAMM-A-056.1.

Gordon, I.J., and Illius, A.W. 1988. Incisor Arcade Structure and Diet Selection in Ruminants. Funct. Ecol. 2(1): 15. doi: $10.2307 / 2389455$.

Hofmann, R.R. 1989. Evolutionary steps of ecophysiological adaptation and diversification of ruminants: A comparative view of their digestive system. Oecologia, 78(4): 443-457. doi:10.1007/BF00378733.

Ingold, P., and Blankenhorn, H. 2005. Freizeitaktivitäten im Lebensraum der Alpentiere: Konfliktbereiche zwischen Mensch und Tier; mit einem Ratgeber für die Praxis. Haupt, Bern. 
Koerner, C. 1999. Alpine plant life: Functional ecology of high mountain ecosystems. Springer, Berlin.

Jonas, T., Geiger, F., and Jenny, H. 2008. Mortality pattern of the Alpine chamois: The influence of snowmeteorological factors. Annals of Glaciology, 49(1): 56-62. doi:10.3189/172756408787814735.

Lovari, S., Ferretti, F., Corazza, M., Minder, I., Troiani, N., Ferrari, C., and Saddi, A. 2014. Unexpected consequences of reintroductions: Competition between reintroduced red deer and Apennine chamois. Anim. Conserv. 17(4): 359-370. doi:10.1111/acv.12103.

Mason, T.H.E., Stephens, P.A., Apollonio, M., and Willis, S.G. 2014. Predicting potential responses to future climate in an alpine ungulate: interspecific interactions exceed climate effects. Global Change Biol. 20(12): 3872-3882. doi:10.1111/gcb.12641.

MeteoSwiss 2016. IDAweb. Data portal for teaching and research. Available from http://www.meteoschweiz.admin.ch/web/de/services/datenportal/idaweb.html

Pérez-Barbería, F.J., Gordon, I.J., and Nores, C. 2001. Evolutionary transitions among feeding styles and habitats in ungulates. Evol. Ecol. Res. 3(2): 221-230.

Pérez-Barbería, F.J., Robertson, E., Soriguer, R., Aldezabal, A., Mendizabal, M., and Pérez-Fernández, E. 2007. Why do polygynous ungulates segregate in space? Testing the activity-budget hypothesis in Soay sheep. Ecol. Monogr. 77(4): 631-647. doi:10.1890/06-2088.1.

R Core Team 2016. R: A language and environment for statistical computing. R Foundation for Statistical Computing, Vienna, Austria. Available from https://www.R-project.org/

Ruckstuhl, K.E. 1998. Foraging behaviour and sexual segregation in bighorn sheep. Anim. Behav. 56(1): 99106. doi:10.1006/anbe.1998.0745.

Ruckstuhl, K.E., Festa-Bianchet, M., and Jorgenson, J.T. 2003. Bite rates in Rocky Mountain bighorn sheep (Ovis canadensis): effects of season, age, sex and reproductive status. Behav. Ecol. Sociobiol. 54(2): 167-173.

Schaepman, M.E., Jehle, M., Hueni, A., D'Odorico, P., Damm, A., Weyermann, J., Schneider, F.D., Laurent, V., Popp, C., Seidel, F.C., Lenhard, K., Gege, P., Küchler, C., Brazile, J., Kohler, P., Vos, L. de, Meuleman, K., Meynart, R., Schläpfer, D., Kneubühler, M., and Itten, K.I. 2015. Advanced radiometry measurements and Earth science applications with the Airborne Prism Experiment (APEX). Remote Sensing of Environment, 158: 207219. doi:10.1016/j.rse.2014.11.014. 
Schläpfer, D., and Richter, R. 2002. Geo-atmospheric processing of airborne imaging spectrometry data. Part 1: Parametric orthorectification. Int. J. Remote Sens. 23(13): 2609-2630. doi:10.1080/01431160110115825.

Richter, R., and Schläpfer, D. 2002. Geo-atmospheric processing of airborne imaging spectrometry data. Part 2: Atmospheric/topographic correction. Int. J. Remote Sens. 23(13): 2631-2649. doi:10.1080/01431160110115834.

Schweiger, A.K., Risch, A.C., Damm, A., Kneubühler, M., Haller, R., Schaepman, M.E., Schütz, M., and Rocchini, D. 2015. Using imaging spectroscopy to predict above-ground plant biomass in alpine grasslands grazed by large ungulates. J. Veg. Sci. 26(1): 175-190. doi:10.1111/jvs.12214.

Schweiger, A.K., Schutz, M., Anderwald, P., Schaepman, M.E., Kneubuhler, M., Haller, R., and Risch, A.C. 2015. Foraging ecology of three sympatric ungulate species - Behavioural and resource maps indicate differences between chamois, ibex and red deer. Movement Ecology, 3: 6. doi:10.1186/s40462-015-0033-x.

Shank, C. C. 1985. Inter-and intra-sexual segregation of chamois (Rupicapra rupicapra) by altitude and habitat during summer. Z. Säugetierkd. 50(2): 117-125.

Wilmshurst, J.F., Fryxell, J.M., and Bergman, C.M. 2000. The allometry of patch selection in ruminants. Proc. R. Soc. Lond. B Biol. Sci. 267(1441): 345-349. doi:10.1098/rspb.2000.1007.

Zoller, H. 1995. Vegetationskarte des Schweizerischen Nationalparks. Nationalpark-Forschung in der Schweiz, 85. F. Flück-Wirth, Teufen. 


\section{Tables:}

Table 1: AICc -based selection of models that explain bite and step rates in Alpine chamois (R. rupicapra L., 1758). The three highest ranking models are shown for both step and bite rates. MTCI $=$ Meris Terrestrial Chlorophyll Index; Temp. = temperature; Dayt. $=$ daytime; Obs. $=$ observer; $\mathrm{RPC}=$ relative plant cover; $\mathrm{X}=$ variable was kept in the model; - = variable was excluded from the model

\begin{tabular}{|c|c|c|c|c|c|c|c|c|c|c|}
\hline \multicolumn{2}{|c|}{ Expl. Variables } & MTCI & Slope & Sex & Temp. & Dayt. & Obs. & $\mathrm{RPC}$ & $\triangle \mathrm{AICc}$ & $\begin{array}{c}\text { AICc } \\
\text { weights }\end{array}$ \\
\hline \multirow{6}{*}{ 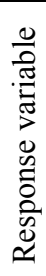 } & \multirow{3}{*}{ Bites / 5 min. } & $\mathbf{X}$ & $\mathbf{X}$ & $\mathbf{X}$ & $\mathbf{X}$ & - & $\mathbf{X}$ & - & $\mathbf{0}$ & 0.47 \\
\hline & & $\mathrm{X}$ & $\mathrm{X}$ & $\mathrm{X}$ & $\mathrm{X}$ & $\mathrm{X}$ & $\mathrm{X}$ & - & 0.06 & 0.46 \\
\hline & & $\mathrm{X}$ & $\mathrm{X}$ & $\mathrm{X}$ & $\mathrm{X}$ & $\mathrm{X}$ & $\mathrm{X}$ & $\mathrm{X}$ & 3.68 & 0.07 \\
\hline & \multirow{3}{*}{ Steps / 5 min. } & - & - & $\mathbf{X}$ & $\mathbf{X}$ & - & - & $\mathbf{X}$ & $\mathbf{0}$ & 0.54 \\
\hline & & - & $X$ & $X$ & $X$ & - & - & $\mathrm{X}$ & 0.94 & 0.34 \\
\hline & & - & $\mathrm{X}$ & $X$ & $\mathrm{X}$ & - & $\mathrm{X}$ & $\mathrm{X}$ & 3.78 & 0.08 \\
\hline
\end{tabular}


Table 2: Effect estimates with standard errors of explanatory variables retained in the final models after model selection according to AICc for bite and step rates in Alpine chamois (R. rupicapra L., 1758).

\begin{tabular}{|c|c|c|c|c|}
\hline & \multicolumn{4}{|c|}{ Dependent variables: } \\
\hline & \multicolumn{2}{|c|}{ Bite rate $\left(5\right.$ minutes $\left.^{-1}\right)$} & \multicolumn{2}{|c|}{ Step rate $\left(5\right.$ minutes $\left.^{-1}\right)$} \\
\hline & Estimate & Std. Error & Estimate & Std. Error \\
\hline Constant & 6.215 & $(0.283)$ & 3.788 & $(0.299)$ \\
\hline MTCI & -0.612 & $(0.164)$ & & \\
\hline Slope & -0.067 & $(0.021)$ & & \\
\hline Sex : Male & 0.157 & $(0.060)$ & -0.215 & $(0.135)$ \\
\hline Temperature & 0.085 & $(0.031)$ & 0.032 & $(0.019)$ \\
\hline Relative plant cover $25-50 \%$ & & & -0.480 & $(0.276)$ \\
\hline Relative plant cover $>50 \%$ & & & -0.519 & $(0.241)$ \\
\hline Observer B & 0.603 & $(0.216)$ & & \\
\hline Observer C & 0.247 & $(0.076)$ & & \\
\hline Observer D & -0.024 & $(0.083)$ & & \\
\hline Sample size & 106 & & 106 & \\
\hline AICc & $1,277.963$ & & $1,212.933$ & \\
\hline
\end{tabular}




\section{Captions for Illustrations:}

Figure 1: Study area with positions of Alpine chamois (R. rupicapra L., 1758) observed feeding at the beginning of observation bouts (dotted circles), and vantage points (white crosses) in the Swiss National Park (SNP).

Figure 2: Histogram of observation distances (along the line of sight) that were calculated in ArcGIS using a 2x2 m digital elevation model, the respective vantage points and the Alpine chamois (R. rupicapra L., 1758) feeding positions.

Figure 3: Effect plots with standard errors (gray) for all variables retained in the final bite rate $(1-5)$ and step rate $(6-8)$ models after model selection based on AICc. 


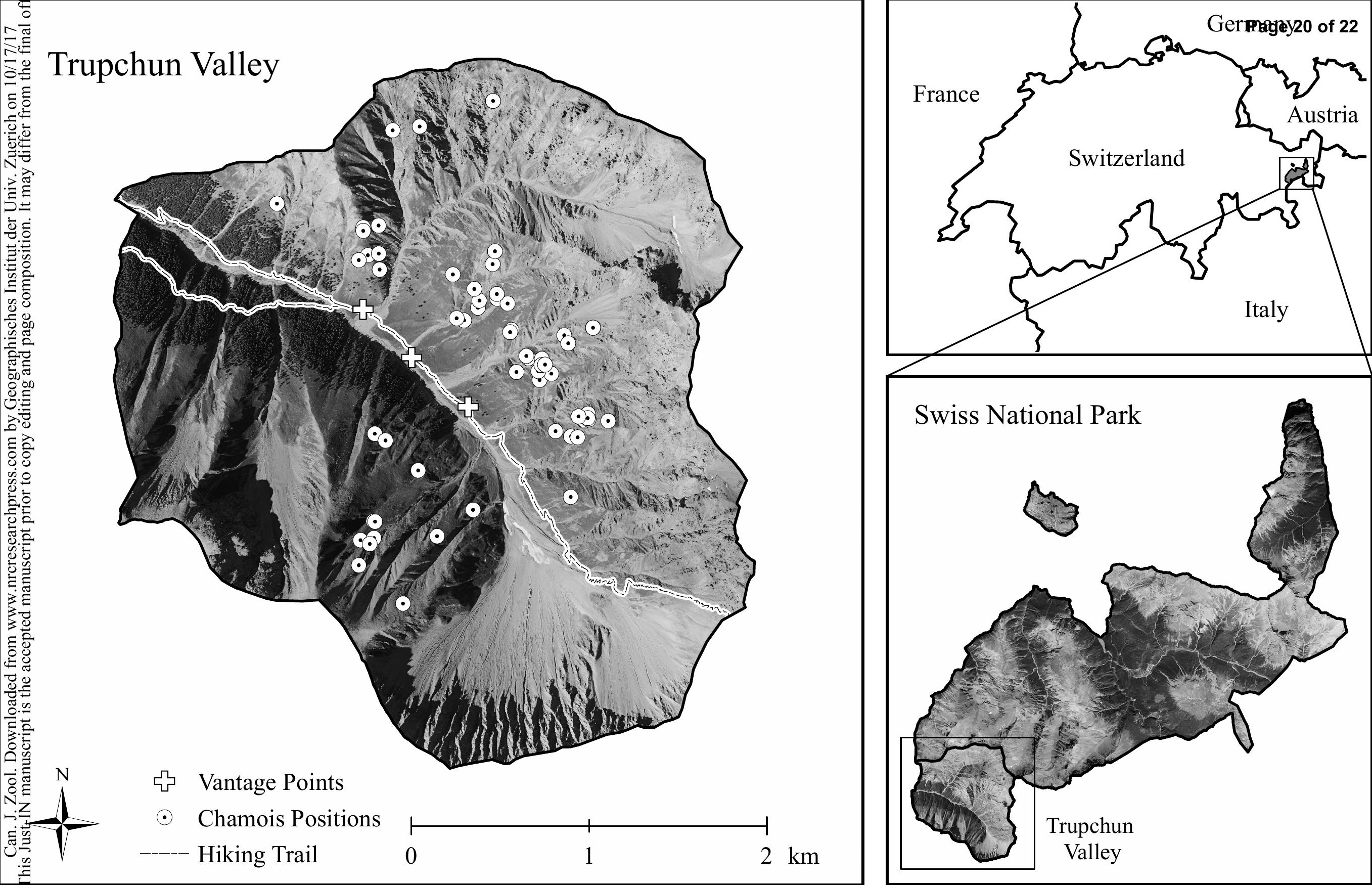




\section{1}

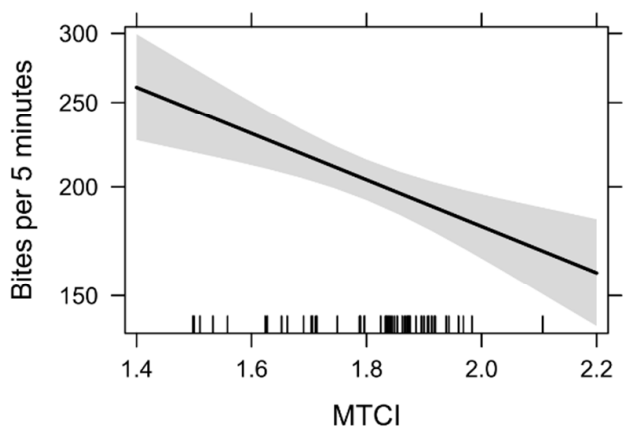

3

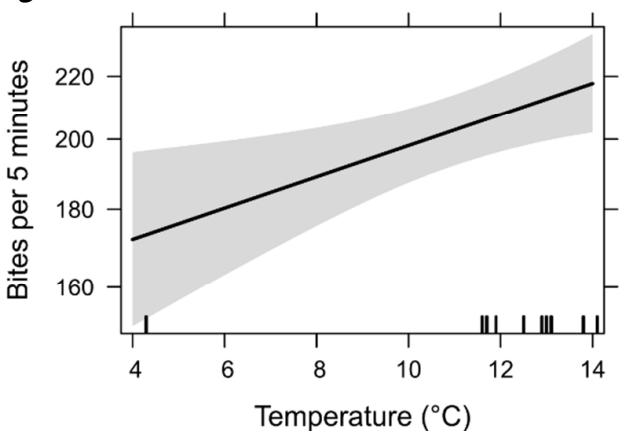

5

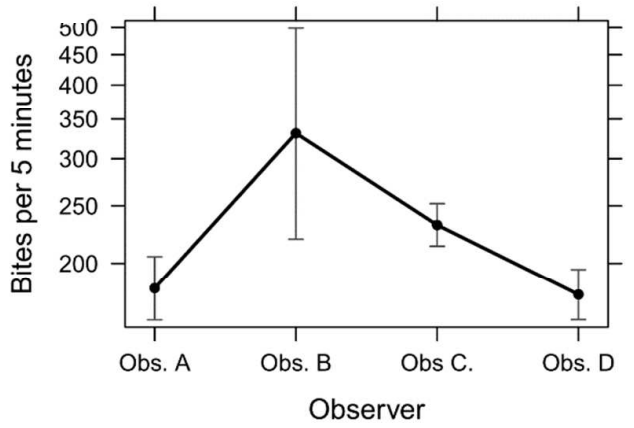

7

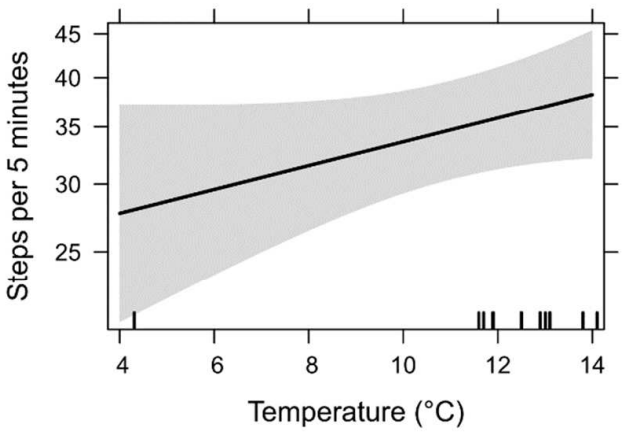

2

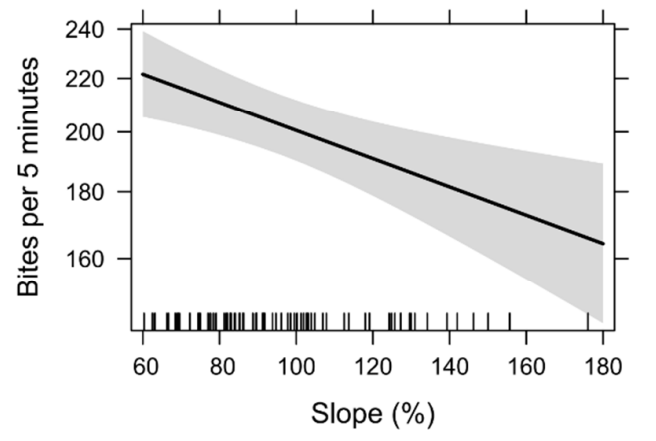

4

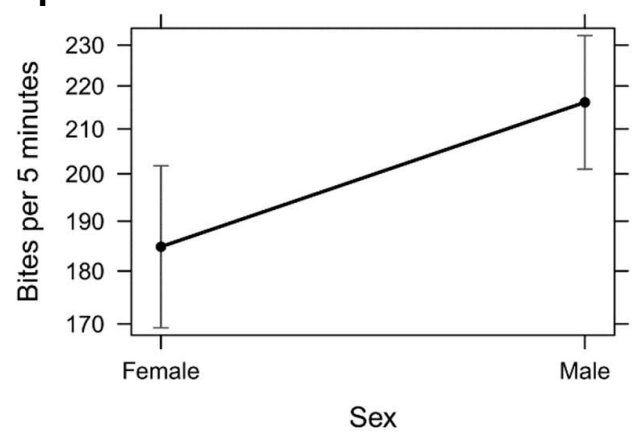

6

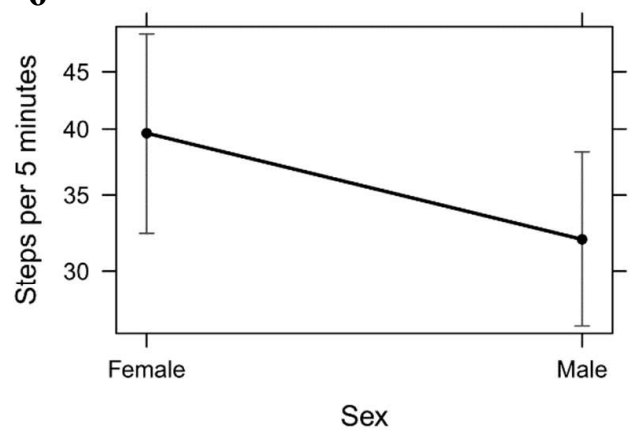

8

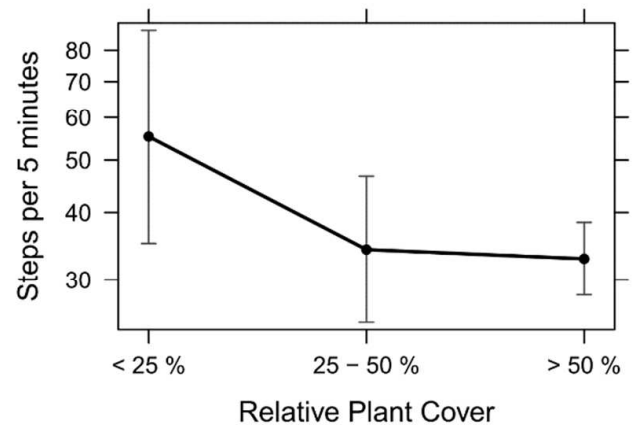

